\title{
Functionalized Stink Bean Pod (Parkia speciosa) Powder for Adsorption of Reactive Dye
}

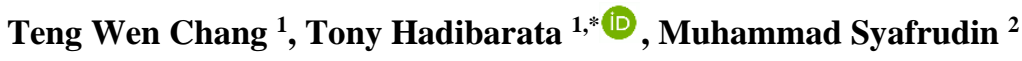 \\ 1 Department of Environmental Engineering, Faculty of Engineering and Science, Curtin University Malaysia, CDT 250, \\ Miri, Malaysia \\ 2 Department of Industrial and Systems Engineering, Dongguk University, Seoul 04620, Korea \\ * Correspondence: hadibarata@ curtin.edu.my
}

Scopus Author ID 16233109100

Received: 20.10.2020; Revised: 5.12.2020; Accepted: 9.12.2020; Published: 15.12.2020

\begin{abstract}
The potential of agricultural waste materials for removing synthetic dye, Remazol Brilliant Blue R (RBBR) and Remazol Brilliant Violet 5R (RBV5) from aqueous solution were investigated. Water pollution is one of the major environmental issues; dyes have contributed enormous damage to water bodies and greatly impact human health due to high toxicity and carcinogenic by nature. Agricultural wastes are sustainable adsorbents and generally low cost, which has the potential to replace traditional activated carbon. Therefore, this study investigated the removal of RBBR and RBV5 dye from the aqueous solution by adding adsorbent through adsorption. Stink bean pod (Parkia speciosa) was selected as the main adsorbent of this study. The experiment was carried out to study the effect of different initial dye concentration, adsorbent dosage, contact time, and $\mathrm{pH}$ level of dye solution. The results have shown that different parameters can affect the removal rate and adsorption capacity of adsorbents in different ways. The adsorption of dye from aqueous solution onto adsorbent was assessed using Fourier Transform Infrared Spectroscopy (FTIR) to determine the functional groups of adsorbent before and after the adsorption process. The FTIR results show that the functional group would affect the removal rate and adsorption capacity of adsorbents. The present study indicates that $83.35 \%$ of RBBR with the adsorption capacity of $1.23 \mathrm{mg} / \mathrm{g}$ was removed by a $3 \mathrm{~g}$ stink bean pod. In comparison, $80.07 \%$ of RBV5 with the adsorption capacity of $1.22 \mathrm{mg} / \mathrm{g}$ was removed by a $3 \mathrm{~g}$ stink bean pod. Design-Expert software was used to generate the equation, which represents the behavior for the adsorption of RBBR and RBV5 dye. The results proved that stink bean pod was promising material as an alternative adsorbent for the removal of dye from aqueous solution.
\end{abstract}

Keywords: Adsorption; Remazol brilliant blue r; Remazol brilliant violet 5r.

(C) 2020 by the authors. This article is an open-access article distributed under the terms and conditions of the Creative Commons Attribution (CC BY) license (https://creativecommons.org/licenses/by/4.0/).

\section{Introduction}

Water pollution is one of the most serious environmental issues that affect living organisms in various aspects. Humans required freshwater to survive; the study reported that water pollution has caused nearly 1.7 million children to die under the age of 5. Furthermore, studies indicate only $0.5 \%$ of fresh water on earth is drinkable, which serves daily human needs, while the rest $97 \%$ is salt water and $2.5 \%$ remaining frozen or stored as groundwater. Thus, it has clearly shown the importance of conserving clean water. The sources of water pollutants can be categorized into point source and non-point source. The major contributions of water pollution, generally including industrial and agricultural sectors, are due to the direct discharge of effluents into nearby water bodies, especially in developing countries [1-3]. Since 19- 
century synthetic dyes have been utilized in many productions and widespread throughout the world, there are more than 100 thousand commercial dyes with a wide range of colors in today's market, which produce up to 700 thousand tons of dyes each year [4]. Synthetic dyes are generally low-cost, diverse selection of colors, able to provide vivid colors, easy to obtain, and apply on the product, which resulted in widespread and huge production of synthetic dye $[5,6]$. The direct discharge of dye effluents from the textile industry is high toxicity, carcinogenic, and resistant to microbial degradation. The concentration of dye particles can be accumulated in a living organism such as edible fish, eventually, affect the whole food chain, and this process is known as the bioaccumulation effect [7].

RBBR and RBV5 dyes are significant reactive dyes and are commonly used in the textile industry. Both dyes are anthraquinone based, which indicates highly toxic resistance to temperature, water, and sunlight. A small amount $(<1 \mathrm{ppm})$ of industrial dye can affect the transparency of water; the direct discharge of industrial dye effluents to the nearby water bodies can affect the visibility of the living organism in the water, eventually threatening their life [8]. This water pollution issue has drawn many researchers' awareness to solve the issue by proposed various studies and research experiments to eliminate dye particles in the wastewater.

Organic pollutants can be classified into three main categories: biological, physical, and chemical methods [9-13].

The adsorption process is effective and easy to apply for decolourizing color from the dye effluence. Agriculture sectors can be defined as the cultivation of crops, livestock, and poultry that support daily food sources. Agriculture increases the economic development of many developing countries tremendously, which contributed to a certain part of the citizen's in-per capita income but ended up in Municipal Solid Waste (MSW) due to excess amount of food or improper food storage $[14,15]$. Thus, agricultural waste is generally low-cost, effective, and easy to obtain, which has the potential to replace high-cost traditional adsorbent in the adsorption process. Based on the previous studies, many researchers have proven that agricultural waste can eliminate color from dye effluents [16,17]. However, various agricultural waste has different characteristics that resulted in different adsorption ability; thus, agricultural waste's adsorption capacity is required to be investigated. This experiment's main objective is to investigate stink bean pod (SBP) ability in the adsorption of RBBR and RBV5 dyes and the effect of several parameters on the adsorption process. Moreover, the characteristic of SBP, adsorption isotherm, and kinetic studies were investigated.

\section{Materials and Methods}

\subsection{Dye solution and adsorbent.}

Remazol brilliant blue r (RBBR) and Remazol brilliant violet 5r (RBV5) were obtained from Sigma-Aldrich with high laboratory grade. The physicochemical characteristics of the dye have shown in Table 1 . The stock solution was prepared by dissolved $1 \mathrm{~g}$ of synthetic dye in 1 liter of distilled water as the main dye solution. A set of stock solutions with a concentration of $30 \mathrm{mg} / \mathrm{L}, 35 \mathrm{mg} / \mathrm{L}, 40 \mathrm{mg} / \mathrm{L}, 45 \mathrm{mg} / \mathrm{L}$, and $50 \mathrm{mg} / \mathrm{L}$ was prepared for RBBR and RBV5 dyes separately from the main dye solution. The stink bean pod (SBP) was collected from a local market and cleaned with distilled water to remove dirt and avoid any impurities remain. SBP adsorbent was placed and dried in the oven at $105^{\circ} \mathrm{C}$ for 24 hours and blended into powder form, which then is stored in an airtight container at room temperature. 
Table 1. Physical and chemical characteristics of PR and RBBR.

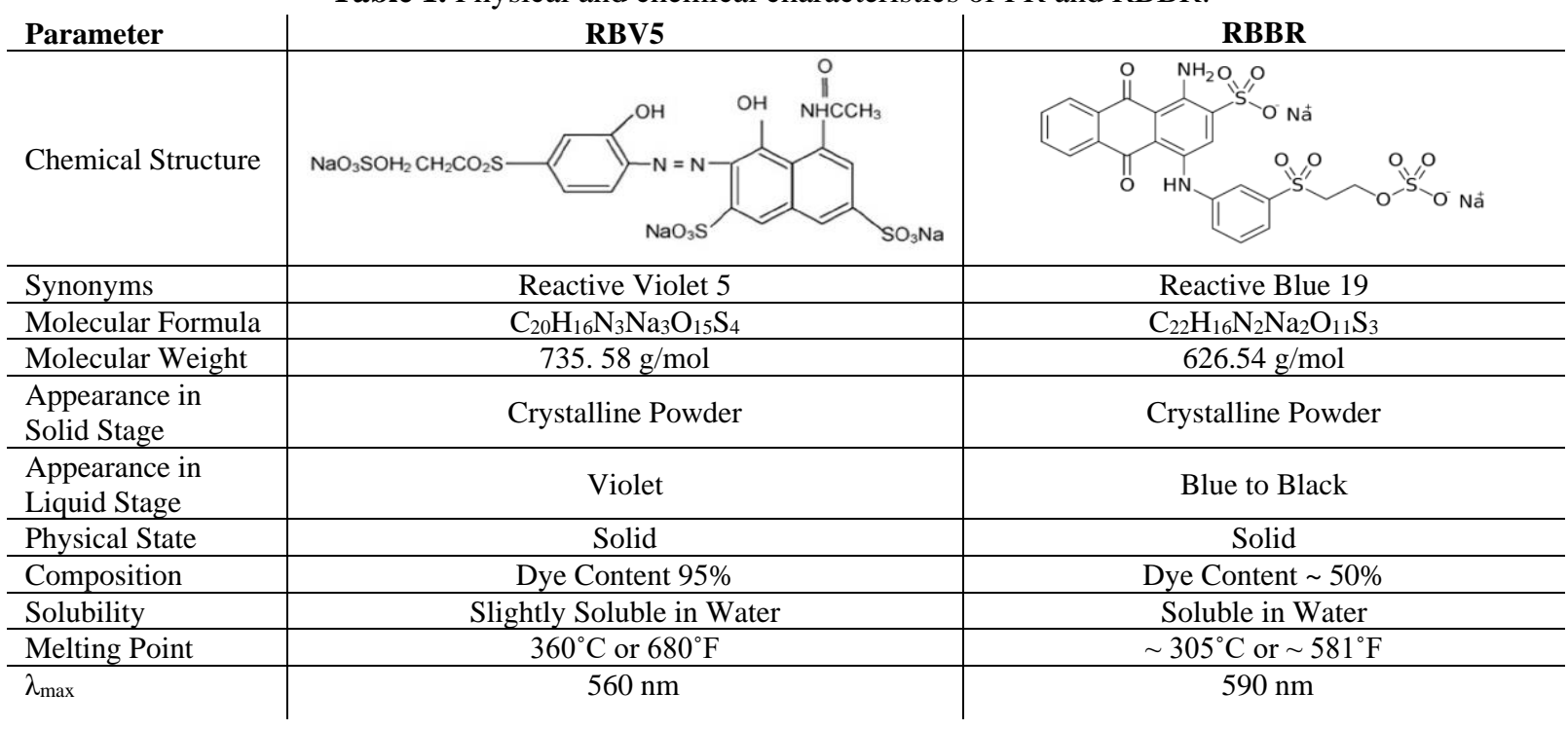

\subsection{FTIR.}

Fourier Transform Infrared Spectroscopy (FTIR) (Agilent Model: Cary 630) analysis was performed to determine the surface functional groups of adsorbents. It was recorded in the spectral range varied from $650 \mathrm{~cm}^{-1}$ to $4000 \mathrm{~cm}^{-1}$.

\subsection{Equilibrium study.}

Adsorption experiment was conducted in 100-ml Erlenmeyer flasks containing $30 \mathrm{ml}$ solution and dried SBP powder of dye $(3 \mathrm{~g})$. The flask was sealed and agitated using a mechanical shaker $(120 \mathrm{rpm})$ at room temperature $\left( \pm 27^{\circ} \mathrm{C}\right)$. This test was conducted for the five proposed effect parameters, which included concentration, contact time, adsorbent dosage, molecular size, and $\mathrm{pH}$. In order to obtain a reliable result, the test was conducted for each parameter would repeat two to three times. The kinetics was studied for 2 hours. The sample solution was filtered by using the Advantec filter paper. The removal of dye was measured by calculating the decrease of absorbance at $590 \mathrm{~nm}$ (RBBR) and $560 \mathrm{~nm}$ (RBV5) on the UV spectrum (Perkin Elmer).

The dye removal (\%) and adsorption capacity $\mathrm{q}_{\mathrm{e}}(\mathrm{mg} / \mathrm{g})$, was calculated by:

$$
\text { Color removal }(\%)=\frac{\mathrm{C}_{\mathrm{i}}-\mathrm{C}_{\mathrm{f}}}{\mathrm{C}_{\mathrm{i}}} \times 100
$$

$$
\text { Adsorption capacity }(\mathrm{mg} / \mathrm{g})=\frac{\mathrm{C}_{\mathrm{i}}-\mathrm{C}_{\mathrm{f}}}{\mathrm{M}} \times \mathrm{V}
$$

where $C_{i}$ is the initial concentration of dye solution $(\mathrm{mg} / \mathrm{L}), \mathrm{C}_{\mathrm{f}}$ is the final concentration of dye solution after adsorption ( $\mathrm{mg} / \mathrm{L}), \mathrm{M}$ is the mass of adsorbent $(\mathrm{gm})$, and $\mathrm{V}$ is the volume of dye solution (L).

\subsection{Isotherm and kinetic studies.}

Three models were used in this research's isotherm study, including Langmuir isotherm, Freundlich isotherm, and Dubinin-Radushkevich isotherm. Langmuir isotherm was used to contrast and quantify the adsorption ability of adsorbents also describe the adsorption in the gas-solid phase. It considers the surface coverage by balancing the dynamic equilibrium and 
adsorption relative rates. Freundlich isotherm has high correlation coefficients and is widely applicable to the adsorption process on the heterogonous surface (mainly organic compound) and multilayers with non-uniform adsorption heat distributions. The slope's variation for adsorption intensity is between 0 to 1 ; the closer the value to 0 means, the more heterogeneous it is. Dubinin-Radushkevich isotherm considers the effect of adsorbent-adsorbate interaction with a Gaussian energy distribution onto a heterogeneous surface. The equation of those isotherms is presented as following [18]:

Langmuir equation:

$$
\frac{\mathrm{C}_{\mathrm{e}}}{\mathrm{q}_{\mathrm{e}}}=\frac{1}{\mathrm{q}_{\mathrm{m}} \mathrm{K}_{\mathrm{L}}}+\frac{\mathrm{C}_{\mathrm{e}}}{\mathrm{q}_{\mathrm{m}}}
$$

Freundlich:

$\log \mathrm{q}_{\mathrm{e}}=\log \mathrm{K}_{\mathrm{F}}+1 / \mathrm{n} \log \mathrm{C}_{\mathrm{e}}$

Dubinin-Radushkevich Equation:

$$
\ln q_{e}=\ln q_{m}-\beta \varepsilon^{2}, E=\frac{1}{\sqrt{-2 \beta}}
$$

Where, $\mathrm{C}_{\mathrm{e}}$ is the concentration of adsorbate at equilibrium $(\mathrm{mg} / \mathrm{g}), \mathrm{q}_{\mathrm{e}}$ is the amount of adsorbate at equilibrium $(\mathrm{mg} / \mathrm{g}), \mathrm{q}_{\mathrm{m}}$ is equal to $\mathrm{q}_{\mathrm{e}}$, and $\mathrm{K}_{\mathrm{L}}$ is Langmuir constant related to adsorption capacity $(\mathrm{L} / \mathrm{mg}), \mathrm{K}_{\mathrm{F}}$ is adsorption capacity $(\mathrm{mg} / \mathrm{g}), E$ is the adsorption energy $\left(\mathrm{kJmol}^{-1}\right), \beta$ is Dubinin-Radushkevich constant, and $\varepsilon$ is Polanyi potential, and $1 / \mathrm{n}$ is adsorption intensity.

The three models (pseudo-first-order, pseudo-second-order, and Intraparticle diffusion) were used to analyze the kinetics of the adsorption process as follows:

Pseudo-first-order rate law: $\quad$ In $\left[\mathrm{q}_{\mathrm{e}}-\mathrm{q}(\mathrm{t})\right]=$ In $\mathrm{q}_{\mathrm{e}}-\mathrm{k}_{1} \mathrm{t}$

Pseudo-second-order rate law : $\quad \frac{t}{q(t)}=\frac{t}{q_{e}}+\frac{1}{k_{2} q_{e}^{2}}$

Intraparticle diffusion equation: $\quad q_{t}=K_{p} \sqrt{t}+C$

where $\mathrm{q}_{\mathrm{e}}$ is adsorption capacity at equilibrium time $(\mathrm{mg} / \mathrm{g}), \mathrm{q}(\mathrm{t})$ is the amount of adsorbate adsorbed at contact time $\mathrm{t}(\mathrm{mg} / \mathrm{g}), \mathrm{k}_{1}$ is the pseudo-first-order rate constant $\left(\mathrm{min}^{-1}\right)$, and $\mathrm{t}$ is contact time with the adsorbent $(\mathrm{min})$, and $\mathrm{k}_{2}$ is the pseudo-second-order rate constant $(\mathrm{g} /(\mathrm{mg}$ $\min )), q_{t}$ is the amount of adsorbate at any time $\mathrm{t}(\mathrm{mg} / \mathrm{g}), K_{\text {diff }}$ is the intraparticle diffusion rate constant $\left(\mathrm{mg} / \mathrm{g} \min ^{1 / 2}\right), \mathrm{C}$ is the interception, and $t$ is the contact time with the adsorbent ( $\mathrm{min}$ ).

\section{Results and Discussion}

\subsection{Calibration Curve.}

The calibration curves of SBP adsorption on RBBR and RBV5 dyes were generated and shown in Fig. 1. The concentration rate for both dyes is from $10 \mathrm{mg} / \mathrm{L}$ to $50 \mathrm{mg} / \mathrm{L}$. From this study, the wavelength of the peak value for RBBR is $590 \mathrm{~mm}$, and RBV5 is $560 \mathrm{~mm}$.

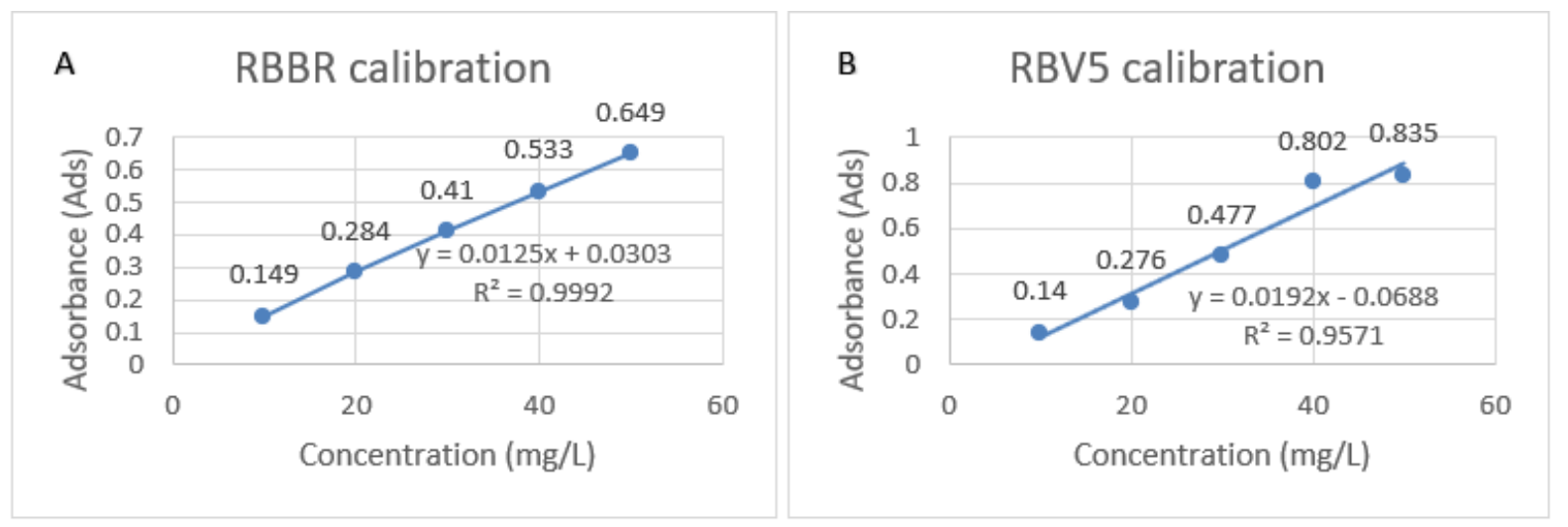

Figure 1. Calibration plot of SBP adsorption on RBBR dye (A); RBV5 dye (B). 


\subsection{Adsorption Capacity.}

The tested parameters are standardized to $30 \mathrm{~g}$ of SBP adsorbent dosage, $8 \mathrm{pH}$ level, and $30 \mathrm{mg} / \mathrm{L}$ of dye concentration. The reason to standardize the parameters is to identify the equilibrium of adsorption, obtain more accurate results from color removal percentage, and minimize errors to determine SBP adsorbent at equilibrium condition. The color removal percentage for both RBBR and RBV5 dyes was lower than $50 \%$ shown in Table 2 . The highest $\%$ color removal rate was achieved at $38.08 \%$ for RBBR dye and $41.22 \%$ for RBV5. The adsorption for RBBR and RBV5 dyes have reached the equilibrium at the contact time of 60 minutes. Fig. 2 has shown the color removal percentage and contact time where the equilibrium of both RBBR and RBV5 dyes adsorption has reached.

Table 2. Color removal \% and adsorption capacity (mg/g) for RBBR and RBV5 dyes.

\begin{tabular}{l|c|c|c|c}
\multirow{2}{*}{ Contact Time (min) } & \multicolumn{2}{|c}{ RBBR } & \multicolumn{2}{c}{ RBV5 } \\
\cline { 2 - 5 } & \% Color Removal & $\begin{array}{c}\text { Adsorption Capacity } \\
(\mathbf{m g} / \mathbf{g})\end{array}$ & \% Color Removal & $\begin{array}{c}\text { Adsorption } \\
\text { Capacity (mg/g) }\end{array}$ \\
\hline 0 & 0 & 0 & 0 & 0 \\
\hline 30 & 26.76 & 0.87 & 9.16 & 0.27 \\
\hline 60 & 38.08 & 1.23 & 41.22 & 1.22 \\
\hline 90 & 13.89 & 0.45 & 23.82 & 0.70 \\
\hline 120 & 19.30 & 0.62 & 30.60 & 0.90 \\
\hline 150 & 25.73 & 0.83 & 26.38 & 0.78
\end{tabular}

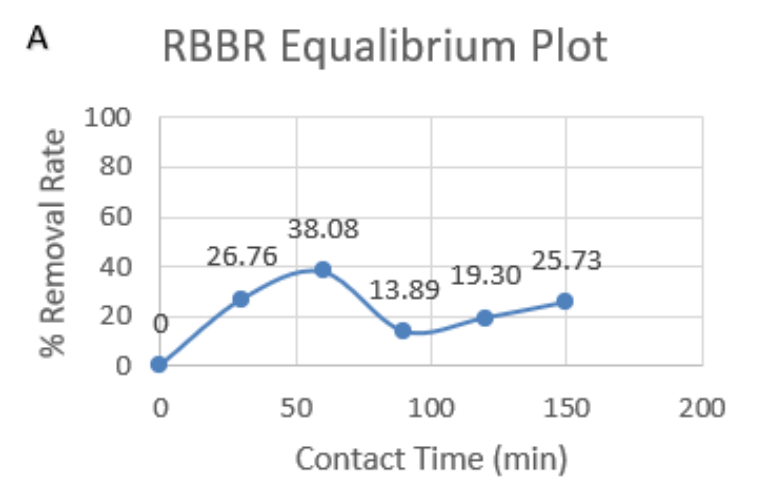

B $\quad$ RBV5 Equalibrium Plot

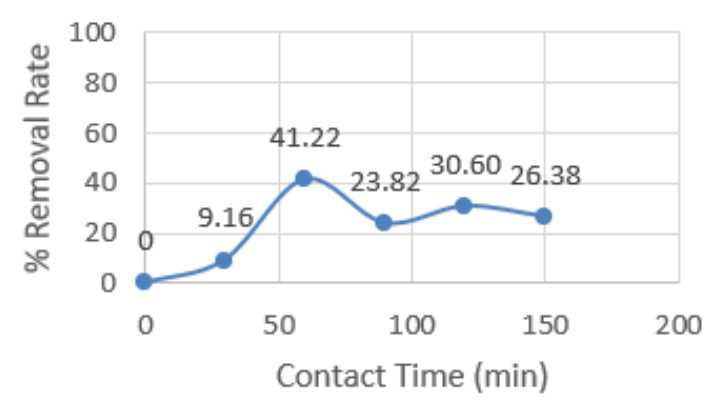

Figure 2. Equilibrium graph for RBBR dye (A); RBV5 dye (B).

\subsection{Batch studies.}

Table 3 and Table 4 show a list of color removal rates for dye adsorption with different effect parameters generated by Design-Expert software. The initial concentration of both dyes' solution ranges from $10 \mathrm{mg} / \mathrm{L}$ to $50 \mathrm{mg} / \mathrm{L}$. The amount of SBP adsorbent added into dye solution range from $1 \mathrm{~g}$ to $5 \mathrm{~g}$. This research experiment was tested in the $\mathrm{pH}$ level of dye solution range from $\mathrm{pH} 5$ to 9 . The contact time tested for this research experiment range from 30 to 60 minutes. Other parameters were kept constant, and the percentage of removal rate was eventually calculated. The highest color removal rate of SBP in RBBR and RBV5 dye resulted in $83.35 \%$ and $80.07 \%$, respectively. Both dyes achieved the highest color removal rate at 30 minutes of contact time, agitation speed of $120 \mathrm{rpm}, 9 \mathrm{pH}$ level, the dye solution concentration at $10 \mathrm{mg} / \mathrm{L}$, and constant room temperature $\left( \pm 27^{\circ} \mathrm{C}\right)$ as shown in Table 3 and Table 4.

Figure 3 shows the $3 \mathrm{D}$ response surface with different combined effects on RBBR and RBV5 dye adsorption, respectively. 
Table 3. Experimental results for RBBR dye with four variables and observed response.

\begin{tabular}{|c|c|c|c|c|c|}
\hline Run & $\begin{array}{l}\text { Adsorbent } \\
\text { Dosage (g) }\end{array}$ & $\begin{array}{l}\text { Contact Time } \\
\text { (min) }\end{array}$ & pH level & $\begin{array}{l}\text { Concentration } \\
(\mathrm{mg} / \mathrm{L})\end{array}$ & $\begin{array}{l}\% \text { Color } \\
\text { Removal }\end{array}$ \\
\hline 1 & 1 & 40 & 7 & 30 & 41.16 \\
\hline 2 & 5 & 30 & 5 & 50 & 46.57 \\
\hline 3 & 3 & 40 & 3 & 30 & 34.73 \\
\hline 4 & 3 & 40 & 7 & 30 & 27.27 \\
\hline 5 & 3 & 50 & 7 & 30 & 29.33 \\
\hline 6 & 1 & 60 & 9 & 10 & 83.35 \\
\hline 7 & 3 & 40 & 5 & 30 & 44.51 \\
\hline 8 & 5 & 40 & 7 & 30 & 50.42 \\
\hline 9 & 1 & 60 & 9 & 50 & 41.68 \\
\hline 10 & 1 & 30 & 9 & 50 & 41.68 \\
\hline 11 & 3 & 50 & 5 & 30 & 65.35 \\
\hline 12 & 5 & 60 & 9 & 10 & 60.20 \\
\hline 13 & 5 & 30 & 9 & 50 & 28.30 \\
\hline 14 & 5 & 60 & 9 & 50 & 42.71 \\
\hline 15 & 5 & 60 & 5 & 50 & 5.40 \\
\hline 16 & 5 & 50 & 7 & 30 & 43.38 \\
\hline 17 & 5 & 30 & 5 & 10 & 49.40 \\
\hline 18 & 5 & 60 & 5 & 10 & 66.89 \\
\hline 19 & 1 & 60 & 5 & 50 & 9.26 \\
\hline 20 & 5 & 30 & 9 & 10 & 71.26 \\
\hline 21 & 1 & 60 & 5 & 10 & 62.77 \\
\hline 22 & 3 & 60 & 7 & 30 & 78.72 \\
\hline 23 & 3 & 50 & 7 & 50 & 42.71 \\
\hline 24 & 3 & 50 & 7 & 10 & 80.01 \\
\hline 25 & 3 & 30 & 9 & 30 & 65.60 \\
\hline 26 & 1 & 30 & 5 & 10 & 45.28 \\
\hline 27 & 5 & 60 & 7 & 30 & 70.75 \\
\hline 28 & 3 & 30 & 7 & 30 & 51.97 \\
\hline 29 & 1 & 30 & 9 & 10 & 44.76 \\
\hline 30 & 1 & 30 & 5 & 50 & 4.12 \\
\hline
\end{tabular}

Table 4. Experimental results for RBV5 dye with four variables and observed response.

\begin{tabular}{|c|c|c|c|c|c|}
\hline Run & $\begin{array}{l}\text { Adsorbent } \\
\text { Dosage (g) }\end{array}$ & $\begin{array}{l}\text { Contact Time } \\
\text { (min) }\end{array}$ & pH level & $\begin{array}{l}\text { Concentration } \\
(\mathrm{mg} / \mathrm{L})\end{array}$ & $\begin{array}{l}\text { \% Color } \\
\text { Removal }\end{array}$ \\
\hline 1 & 1 & 40 & 7 & 30 & 40.67 \\
\hline 2 & 5 & 30 & 5 & 50 & 67.24 \\
\hline 3 & 3 & 40 & 3 & 30 & 63.39 \\
\hline 4 & 3 & 40 & 7 & 30 & 66.32 \\
\hline 5 & 3 & 50 & 7 & 30 & 76.04 \\
\hline 6 & 1 & 60 & 9 & 10 & 80.07 \\
\hline 7 & 3 & 40 & 5 & 30 & 69.44 \\
\hline 8 & 5 & 40 & 7 & 30 & 63.58 \\
\hline 9 & 1 & 60 & 9 & 50 & 70.72 \\
\hline 10 & 1 & 30 & 9 & 50 & 67.06 \\
\hline 11 & 3 & 50 & 5 & 30 & 61.93 \\
\hline 12 & 5 & 60 & 9 & 10 & 68.34 \\
\hline 13 & 5 & 30 & 9 & 50 & 62.29 \\
\hline 14 & 5 & 60 & 9 & 50 & 66.51 \\
\hline 15 & 5 & 60 & 5 & 50 & 54.78 \\
\hline 16 & 5 & 50 & 7 & 30 & 71.45 \\
\hline 17 & 5 & 30 & 5 & 10 & 68.52 \\
\hline 18 & 5 & 60 & 5 & 10 & 53.50 \\
\hline 19 & 1 & 60 & 5 & 50 & 72.37 \\
\hline 20 & 5 & 30 & 9 & 10 & 78.23 \\
\hline 21 & 1 & 60 & 5 & 10 & 76.95 \\
\hline 22 & 3 & 60 & 7 & 30 & 66.87 \\
\hline 23 & 3 & 50 & 7 & 50 & 70.36 \\
\hline 24 & 3 & 50 & 7 & 10 & 62.66 \\
\hline 25 & 3 & 30 & 9 & 30 & 75.30 \\
\hline 26 & 1 & 30 & 5 & 10 & 65.23 \\
\hline 27 & 5 & 60 & 7 & 30 & 50.38 \\
\hline 28 & 3 & 30 & 7 & 30 & 48.19 \\
\hline 29 & 1 & 30 & 9 & 10 & 71.09 \\
\hline 30 & 1 & 30 & 5 & 50 & 70.54 \\
\hline
\end{tabular}



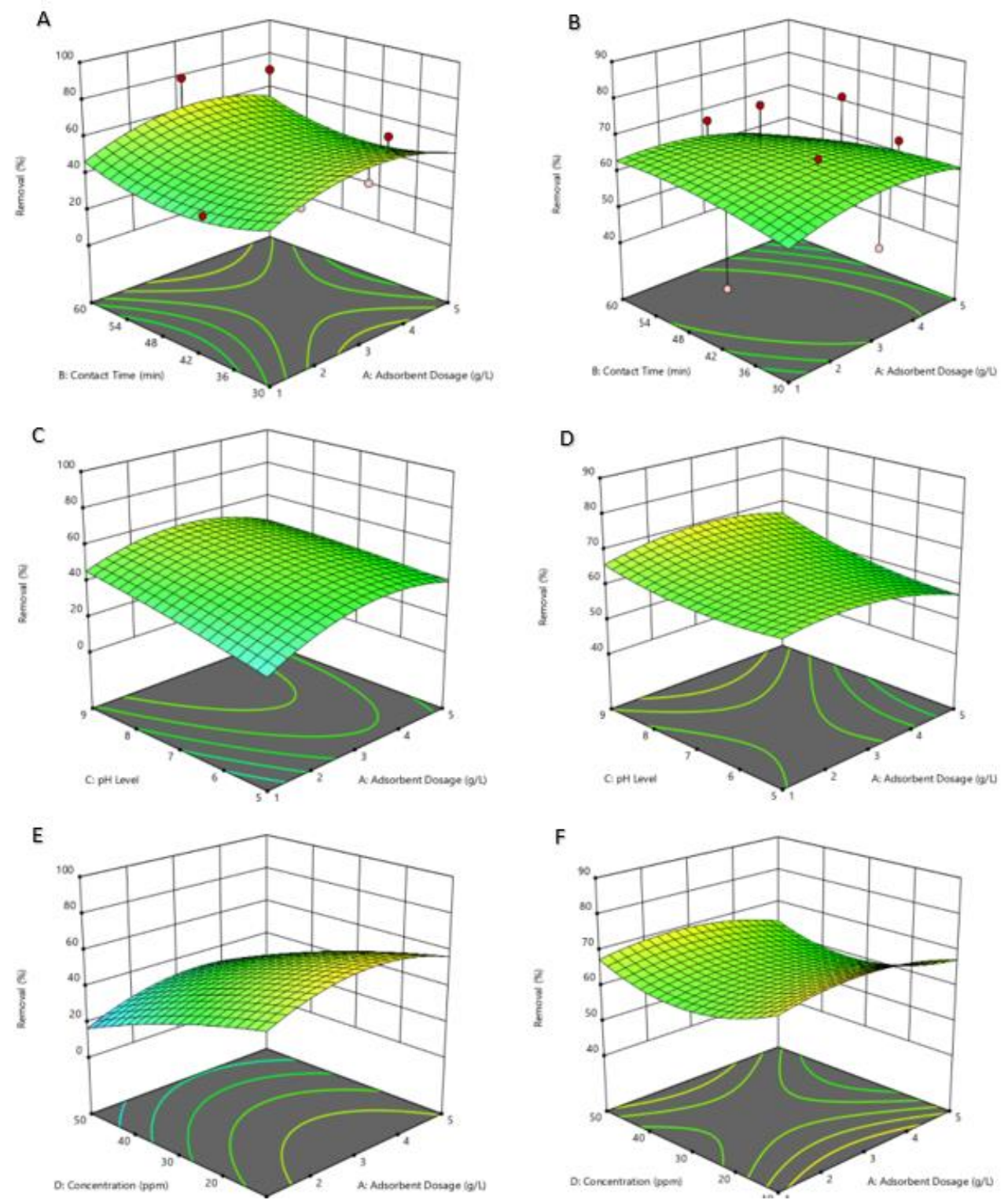

Figure 3. 3D response surfaces with the combined effect of adsorbent dosage ( $\mathrm{g} / \mathrm{L})$ and contact time (min) for RBBR dye (A); RBV5 dye (B) (Red dots indicate the design point); the combined effect of adsorbent dosage $(\mathrm{g} / \mathrm{L})$ and $\mathrm{pH}$ level for RBBR dye (C); RBV5 dye (D); the combined effect of adsorbent dosage $(\mathrm{g} / \mathrm{L})$ and concentration (ppm) for RBBR dye (E); RBV5 (F).

Figure 3A shows the percentage of color removal for RBBR dye adsorption increase from $44.76 \%$ to $83.35 \%$ with the increase of contact time sorption from 30 minutes to 60 minutes. Figure 3B shows the percentage of color removal for RBV5 dye adsorption increase from $71.09 \%$ to $83.35 \%$. This result can be explained as an increase in contact time will also increase the color removal rate that meets the theoretical results, which indicate high accuracy of this experiment due to an increase in contact time will allow higher access of binding sites for the adsorbents to contact dye solution results in a higher percentage of color removal rate achieved for the adsorption process [19]. Moreover, the adsorption of RBBR and RBV5 in this experiment reached the equilibrium stage at the contact time of 60 minutes and decreased the progress of adsorption when the contact time increases to 150 minutes, as shown in Figure 2. This can be explained as an equilibrium state reflected in the time and amount of dye adsorbed at the adsorbent's maximum adsorption capacity under the operating conditions. At equilibrium state, the adsorption process is limited by the mass transfer of adsorbate molecules from the 
dye solution to the absorbance's external surface, resulting in a slower rate of molecules transfer from dye solution to the absorbance.

Figure $3 \mathrm{C}$ shows the color removal rate for RBBR dye adsorption decreases from $83.35 \%$ to $62.77 \%$ when the dye solution decrease to $\mathrm{pH}$ level 5, and Figure 3D shows the color removal rate for RBV5 dye adsorption decreases from $83.35 \%$ to $76.95 \%$ when the dye solution decrease to $\mathrm{pH}$ level 5. This can be explained as RBBR, and RBV5 dyes are anionic dye, indicating anionic emulsion of both dyes has a negative charge and resistance to acid. Besides, at a low $\mathrm{pH}$ level of dye solution, the positive charge on the dye solution interface will increase. The adsorbent surface appears positive charged, resulting in a decrease in cationic dye adsorption [20].

Figure $3 \mathrm{E}$ shows the percentage of color removal for RBBR dye decrease from $83.35 \%$ to $41.68 \%$ as the concentration of dye solution increase from $10 \mathrm{mg} / \mathrm{L}$ to $50 \mathrm{mg} / \mathrm{L}$. Figure $3 \mathrm{~F}$ shows that the percentage of color removal for RBV5 dye decreases from $80.07 \%$ to $70.72 \%$ as the dye solution's concentration increases from $10 \mathrm{mg} / \mathrm{L}$ to $50 \mathrm{mg} / \mathrm{L}$. This can be explained as normal behavior when RBBR and RBV5 dye solution have low concentration; the stink bean pod absorbance can fully absorb the color from the dye solution due to the higher availability of the adsorbent site. As the concentration of RBBR and RBV5 dye increases, the percentage color removal rate decreases, which were attributed to the limitation of active sorption sites on the stink bean pod absorbance available to absorb the dye solution due to the resistance of mass transfer for the dye to be absorbed by the stink bean pod absorbent [21].

\subsection{FTIR.}

The chemical characteristic and functional group at the adsorbent surface could affect the adsorption capacity. The different type of adsorbent has different functional group resulted in different adsorption capacity. Figure 4A shows the infrared spectrum for SBP with a noticeable peak at the $3228 \mathrm{~cm}^{-1}$, which indicates a hydroxyl functional group of alcohols with $\mathrm{O}-\mathrm{H}$ stretch. At peak $2900 \mathrm{~cm}^{-1}$ shows a functional group of Alkanes with $\mathrm{H}$-bonded. While at peak $1595 \mathrm{~cm}^{-1}$ shows a functional group of $\mathrm{C}=\mathrm{C}$ bonds in aromatic rings and the presence of amines functional group with $\mathrm{N}-\mathrm{H}$ bend. The peak at $1021 \mathrm{~cm}^{-1}$ indicates the functional group of Alcohols, Esters, and Carboxylic acids with C-O stretch. At the peak of $649 \mathrm{~cm}^{-1}$, the functional group of Alkyl halides present with a $\mathrm{C}-\mathrm{Br}$ stretch. Noticeable peak and shifting base on the adsorption of RBBR and RBV5 dyes could observe in Figure 4. The SBP adsorbent has reached a peak at $3228 \mathrm{~cm}^{-1}$; after the RBBR dye adsorption, the peak has shifted slightly to $3265 \mathrm{~cm}^{-1}$, and after the RBV5 dye adsorption, the peak has been shifted to $3250 \mathrm{~cm}^{-1}$. These peaks for SBP before and after the adsorption of RBBR and RBV5 dyes attributed to O-H stretch and H-bond, which are categorized under the alcohols and phenols functional group. The second peak of SBP is at $2900 \mathrm{~cm}^{-1}$ after the RBBR and RBV5 dye adsorption; both peaks have a minor change to $2907 \mathrm{~cm}^{-1}$, which indicates alkanes functional group with the bonding of $\mathrm{C}-\mathrm{H}$ stretch. The third peak of SBP is at $1595 \mathrm{~cm}^{-1}$. After the RBBR and RBV5 dye adsorption, both peaks have a slight change to $1603 \mathrm{~cm}^{-1}$, which indicates a weak band of N-H bend and corresponds to the amines functional group. The fourth peak of SBP is at $1021 \mathrm{~cm}^{-1}$ after the adsorption of RBBR dye. The peak remains unchanged at $1021 \mathrm{~cm}-1$. After the adsorption of RBV5 dye, the peak shifted slightly to $1014 \mathrm{~cm}^{-1}$. These peaks categories under the functional group of Alcohols, Esters, and Carboxylic acids with C-O stretch. The nature of functional groups involve (hydrophobic/hydrophilic) present on adsorbent causes various interactions of hydrogen bond and electrostatic attraction of dye particles [22]. 


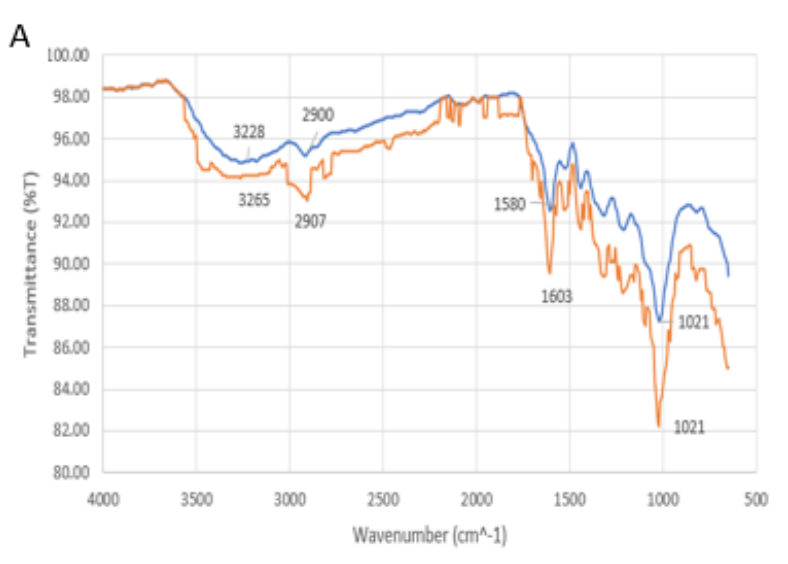

Figure 4. FTIR spectra of SBP before and after adsorption of RBBR dye (A); RBV5 dye (B).

\subsection{Experimental design.}

Design response surface methodology (RSM) is a subset of central composite design (CCD) used to study the effect of four factors on the responses of this adsorption experiment. The CCD method was chosen because it is suitable for fitting a quadratic surface; the optimal conditions for the color removal percentage responses were calculated and input in the RSM method. Therefore, the variance result has been analyzed. The behavior for the adsorption of dye solution can be presented using the optimal predictor quadratic model. According to the analysis of variance (ANOVA), $\mathrm{R}^{2}$ is set close to the value 1 . This is because the $\mathrm{R}^{2}$ value closer to 1 will have a better agreement between experimental and predicted data. The equations to represent the behavior for the adsorption of RBBR dye and RBV5 dye are listed as follows:

RBBR dye adsorption:

$$
\begin{aligned}
Y=58.29625 & +23.11326 x_{1}-3.05488 x_{2}+11.22556 x_{3}-0.938820 x_{4} \\
& +0.020418 x_{1} x_{2}-0.872344 x_{1} x_{3}+0.022891 x_{1} x_{4}-0.078383 x_{2} x_{3} \\
& -0.001691 x_{2} x_{4}+0.084047 x_{3} x_{4}-2.81911 x_{1}^{2}+0.040673 x_{2}^{2} \\
& -0.318289 x_{3}^{2}-0.007977 x_{4}^{2}
\end{aligned}
$$

RBV5 dye adsorption:

$$
\begin{aligned}
Y=66.08498 & +6.71687 x_{1}+0.905728 x_{2}-6.20908 x_{3}-0.849164 x_{4}-0.101726 x_{1} x_{2} \\
& +0.429375 x_{1} x_{3}-0.008000 x_{1} x_{4}-0.008548 x_{2} x_{3}+0.004698 x_{2} x_{4} \\
& -0.049813 x_{3} x_{4}-0.930950 x_{1}^{2}-0.007855 x_{2}^{2}+0.591032 x_{3}^{2} \\
& +0.015745 x_{4}^{2}
\end{aligned}
$$

where $\mathrm{Y}$ is the predicted values of percentage removal rate for adsorption of dye, $x_{1}$ is Adsorbent Dosage, $x_{2}$ is Contact Time, $x_{3}$ is $\mathrm{pH}$ level and $x_{4}$ is the concentration.

\subsection{Comparison of predicted and experimental results.}

Figure 5A shows the different experimental and predicted values for RBBR dye adsorption could be observed. The highest \% color removal rate for RBBR dye adsorption experimental result has shown $83.35 \%$. The highest \% color removal rate for RBBR dye adsorption predicted result is $91.87 \%$. The experimental and predicted results have shown different values, which can cause by several reasons; one of the main reasons is experimental errors might occur during the conducted experiment as the moisture content in the SBP sample is not completely removed; thus, different experimental results can be observed in Figure 5. 
Figure 5B shows that the different experimental and predicted values for RBV5 dye adsorption could be observed. The highest \% color removal rate for RBV5 dye adsorption experimental result has shown $80.07 \%$. The highest \% color removal rate for RBBR dye adsorption predicted result is $94.87 \%$. The experimental and predicted results different can cause by several reasons. One of the reasons is the experiment's environment in which the experimental samples have been tested using the UV-Vis instrument in a humid environment as humidity and temperature can be varied daily result in different experimental and predicted results.
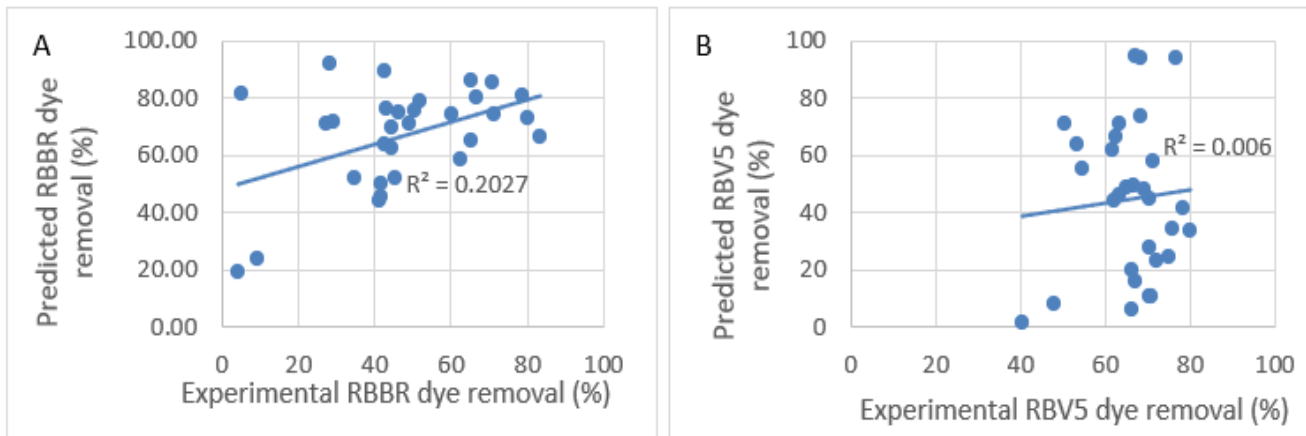

Figure 5. Relationship between predicted and experimental data for adsorption of RBBR (A); RBV5 (B).

\subsection{Isotherm and kinetic studies.}

The adsorption capacity for adsorption of RBBR and RBV5 on stink bean pod was evaluated using Langmuir, Freundlich, and Dubinin-Radushkevich isotherm to analyze the interaction mechanisms between the adsorbent and the adsorbate at a constant temperature as shown in Table 5. Langmuir isotherm, $q_{m}(\mathrm{mg} / \mathrm{g})$ and $K_{L}(\mathrm{mg} / \mathrm{L}) \mathrm{RBBR}$ and RBV5 dyes adsorption values were calculated using a straight-line equation generated from the $\mathrm{C}_{\mathrm{e}} / \mathrm{q}_{\mathrm{e}} \mathrm{vs}$. $\mathrm{C}_{\mathrm{e}}$ graph plotted as shown in Figure 6A. Freundlich isotherm, the $\mathrm{n}$ and $K_{F}(\mathrm{mg} / \mathrm{L}) \mathrm{RBBR}$ and RBV5 dyes adsorption values were calculated from the straight-line equation generated from $\ln \mathrm{q}_{\mathrm{e}} \mathrm{vs} \ln \mathrm{C}_{\mathrm{e}}$ graph plotted as shown in Figure 6B. Dubinin-Radushkevich isotherm, ln qe vs $\varepsilon^{2}$ the graph was plotted as shown in Figure 6C to calculate the value of $q_{m}(\mathrm{mg} / \mathrm{g})$ and E $(\mathrm{kJ} / \mathrm{mg})$. Based on the comparison results obtained among three isotherm models, Freundlich is the best-fitted adsorption data. The equation of both RBBR and RBV5 dyes adsorption isotherm achieved the $\mathrm{R}^{2}$ value nearest to 1 compared to Langmuir and Dubinin-Radushkevich isotherm. Thus, this study shows that Freundlich isotherm is highly reliable and proves to be the best fit for stink bean pod adsorbent from this experimental data. This can be explained as the Freundlich isotherm model is corresponding to the heterogeneous surface binding of the adsorbent surface [23].

The kinetic studies were selected to analyze the experimental data, including pseudofirst-order, pseudo-second-order, and intraparticle diffusion models. The Kinetics results for RBBR and RBV5 dyes adsorption were calculated and shown in Table 6. The pseudo-firstorder with the linear plots of $\ln \left(\mathrm{q}_{\mathrm{e}}-\mathrm{q}_{\mathrm{t}}\right)$ vs. time $(\mathrm{t})$ shows in Figure 7A. The pseudo-secondorder with the linear plots of $\mathrm{t} / \mathrm{q}_{\mathrm{t}}$ vs. time $(\mathrm{t})$ shows in Figure $7 \mathrm{~B}$. The intraparticle diffusion kinetic model with the plots of $\mathrm{q}_{\mathrm{t}} \mathrm{vs} \sqrt{t}$ shows in Figure 7C. Based on this study, the pseudosecond-order kinetic model best fits the adsorption data compared to two other kinetic studies on removing RBBR and RBV5 dyes using stink bean pod adsorbent. In summary, the pseudosecond-order kinetic model is best described the sorption kinetics from the overall rate of 
adsorption and factor of sorption rate due to physiochemical interaction between two phases [24].
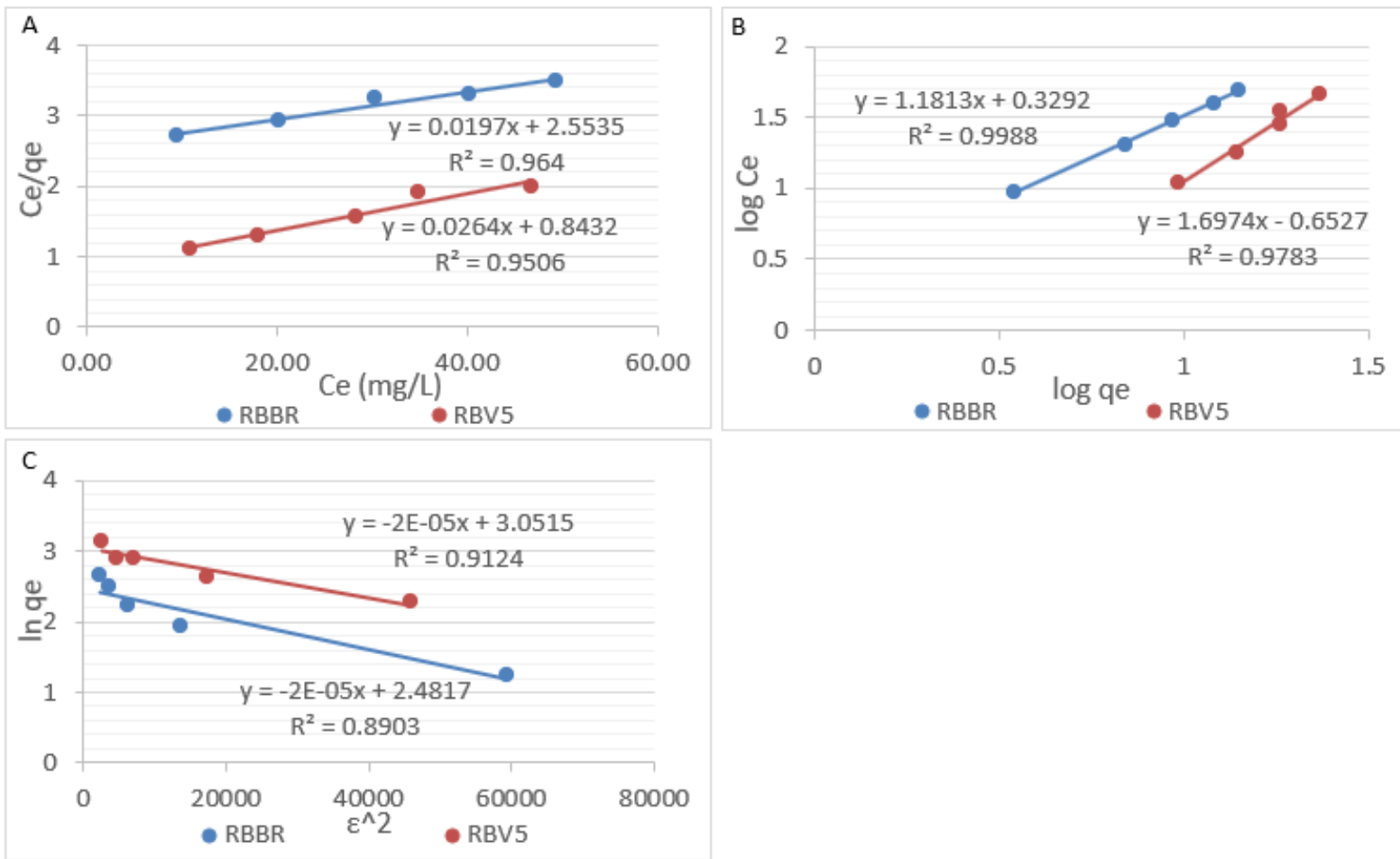

Figure 6. Isotherm model SBP: Langmuir (A); Freundlicch (B); Dubinin-Radushkevich (C).
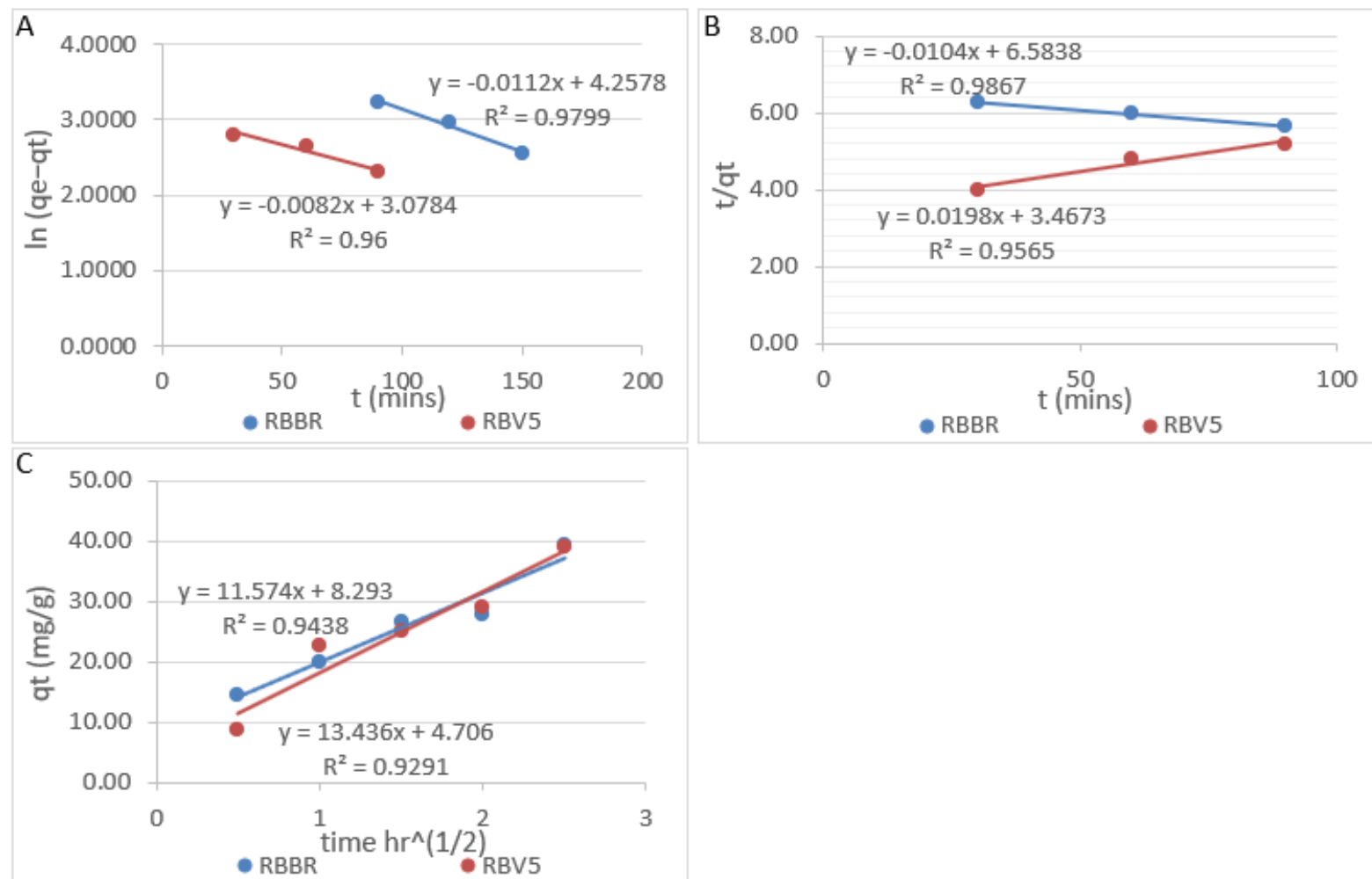

Figure 6. Kinetic models SBP: Pseudo first order (A), Pseudo second-order (B), Intraparticle diffusion (C).

Table 5. Isotherm parameters for adsorption of RBBR and RBV5 dyes on stink bean pod.

\begin{tabular}{l|c|c|c}
\multirow{2}{*}{ Isotherm model } & Adsorption constant & \multicolumn{2}{|c}{ Stink bean pod } \\
\cline { 3 - 4 } & $q_{m}(\mathrm{mg} / \mathrm{g})$ & 51.020 & RBV5 \\
\hline \multirow{3}{*}{ Langmuir } & $K_{L}(\mathrm{mg} / \mathrm{L})$ & 0.008 & 40.650 \\
\cline { 2 - 4 } & $R^{2}$ & 0.964 & 0.029 \\
\hline
\end{tabular}




\begin{tabular}{|c|c|c|c|}
\hline \multirow{2}{*}{ Isotherm model } & \multirow{2}{*}{ Adsorption constant } & \multicolumn{2}{|c|}{ Stink bean pod } \\
\hline & & RBBR & RBV5 \\
\hline \multirow{3}{*}{ Freundlich } & $\mathrm{n}$ & 0.874 & 0.757 \\
\hline & $K_{F}(\mathrm{mg} / \mathrm{L})$ & 2.345 & 0.614 \\
\hline & $R^{2}$ & 0.998 & 0.978 \\
\hline \multirow{4}{*}{ Dubinin-Radushkevich } & $q_{m}(\mathrm{mg} / \mathrm{g})$ & 2.482 & 3.052 \\
\hline & $\varepsilon^{2}$ & 13713.400 & 17409.270 \\
\hline & $\mathrm{E}(\mathrm{kJ} / \mathrm{mg})$ & 1.857 & 1.434 \\
\hline & $R^{2}$ & 0.890 & 0.912 \\
\hline
\end{tabular}

Table 6. Kinetic parameters for adsorption of RBBR and RBV5 dyes on stink bean pod.

\begin{tabular}{l|c|c|c}
\multirow{2}{*}{ Kinetic studies } & \multirow{2}{*}{ Adsorption constant } & RBBR & Rtink bean pod \\
\cline { 3 - 4 } & & 70.65 & 35.57 \\
\hline \multirow{3}{*}{ Pseudo-first-order } & $\mathrm{q}_{\mathrm{e} \text { calculated }}$ & 2.32 & 3.30 \\
\cline { 2 - 4 } & $\mathrm{K}_{1}$ & 0.98 & 0.96 \\
\cline { 2 - 4 } & $\mathrm{R}^{2}$ & 96.15 & 0.50 \\
\hline \multirow{3}{*}{ Pseudo-second-order } & $\mathrm{qe}^{2}$ calculated & 0.008 & 0.957 \\
\cline { 2 - 4 } & $\mathrm{K}_{2}$ & 0.987 & 4.706 \\
\cline { 2 - 4 } Intraparticle diffusion & $\mathrm{R}^{2}$ & 8.293 & 13.436 \\
\cline { 2 - 4 } & $\mathrm{C}$ & 11.574 & 0.929
\end{tabular}

\section{Conclusions}

In conclusion, the stink bean pod adsorbent achieved $83.35 \%$ of the RBBR dye color removal rate and $80.07 \%$ of RBV5 dye color removal. Four parameters were carried out, including adsorbents dosage ( $\mathrm{g}$ ), contact time ( $\mathrm{min}), \mathrm{pH}$ level, and initial concentration $(\mathrm{mg} / \mathrm{L})$ to determine the optimum adsorption condition using central composite design (CCD) equations generated to experiment. To summarize, the relationship of the initial concentration of RBBR and RBV5 dye solution on SBP adsorbent is inversely proportional. The optimum adsorbent dosage for both RBBR and RBV5 dye adsorption is $1 \mathrm{~g}$ instead of $5 \mathrm{~g}$ due to a decrease in the total contact area and insufficient contact time. An increase in the dye solution's $\mathrm{pH}$ level from acidic to alkaline resulted in a higher color removal rate due to the electrostatic attraction for anionic dye solution. Both RBBR and RBV5 dye adsorption achieve equilibrium at 60 minutes, which indicates the maximum capacity for the adsorbent to adsorb dye particles. Three isotherm models were selected from this research project, Langmuir, Freundlich, and Dubinin-Radushevich isotherm; it was observed that the Freundlich isotherm model is best fits by achieving an $\mathrm{R}^{2}$ value of 0.999 for RBBR dye and 0.978 for RBV5 dye adsorption. Besides, three graphs with linear plots for kinetics studies were carried out, and the pseudo-second-order kinetic model achieved an $\mathrm{R}^{2}$ value close to 1 with 0.987 for RBBR dye and 0.96 for RBV5 dye adsorption, which indicates a better correlation coefficient to the other two kinetic models.

\section{Funding}

This research received no external funding.

\section{Acknowledgments}

This research has no acknowledgment.

\section{Conflicts of Interest}

The authors declare no conflict of interest 


\section{References}

1. Hadibarata, T.; Kristanti, R.A.; Mahmoud, A.H. Occurrence of endocrine-disrupting chemicals (EDCs) in river water and sediment of the Mahakam River. J. Water Health 2019, 18, 38-47, https://doi.org/10.2166/wh.2019.100.

2. Hadibarata, T.; Syafiuddin, A.; Ghfar, A.A. Abundance and distribution of polycyclic aromatic hydrocarbons (PAHs) in sediments of the Mahakam River. Mar. Pollut. Bull. 2019, 149, 110650, https://doi.org/10.1016/j.marpolbul.2019.110650.

3. Lee Goi, C. The river water quality before and during the Movement Control Order (MCO) in Malaysia. Case Studies in Chemical and Environmental Engineering 2020, 2, 100027, https://doi.org/10.1016/j.cscee.2020.100027.

4. Katheresan, V.; Kansedo, J.; Lau, S.Y. Efficiency of various recent wastewater dye removal methods: A review. Journal of Environmental Chemical Engineering 2018, 6, 4676-4697, https://doi.org/10.1016/j.jece.2018.06.060.

5. Saeed, A.; Shabir, G. Synthesis and characterization of high wash fastness novel azo reactive dyes incorporating aromatic bridged diamines. Arabian Journal of Chemistry 2018, 11, 111-119, https://doi.org/10.1016/j.arabjc.2014.11.010.

6. El-Aassar, M.R.; Fakhry, H.; Elzain, A.A.; Farouk, H.; Hafez, E.E. Rhizofiltration system consists of chitosan and natural Arundo donax L. for removal of basic red dye. Int. J. Biol. Macromol. 2018, 120, 15081514, https://doi.org/10.1016/j.ijbiomac.2018.09.159.

7. Lellis, B.; Fávaro-Polonio, C.Z.; Pamphile, J.A.; Polonio, J.C. Effects of textile dyes on health and the environment and bioremediation potential of living organisms. Biotechnology Research and Innovation 2019, 3, 275-290, https://doi.org/10.1016/j.biori.2019.09.001.

8. Chatterjee, M.J.; Ahamed, S.T.; Mitra, M.; Kulsi, C.; Mondal, A.; Banerjee, D. Visible-light influenced photocatalytic activity of polyaniline -bismuth selenide composites for the degradation of methyl orange, rhodamine B and malachite green dyes. Appl. Surf. Sci. 2019, 470, 472-483, https://doi.org/10.1016/j.apsusc.2018.11.085.

9. Zhang, X.; Chen, Z.; Shen, J.; Zhao, S.; Kang, J.; Chu, W.; Zhou, Y.; Wang, B. Formation and interdependence of disinfection byproducts during chlorination of natural organic matter in a conventional drinking water treatment plant. Chemosphere 2020, 242, 125227, https://doi.org/10.1016/j.chemosphere.2019.125227.

10. Sidney Santana, C.; Nicodemos Ramos, M.D.; Vieira Velloso, C.C.; Aguiar, A. Kinetic Evaluation of Dye Decolorization by Fenton Processes in the Presence of 3-Hydroxyanthranilic Acid. Int. J. Env. Res. Public Health 2019, 16, https://doi.org/10.3390/ijerph16091602.

11. Hadibarata, T.; Kristanti, R.A. Effect of environmental factors in the decolorization of Remazol Brilliant Blue R by Polyporus sp. S133. Journal of The Chilean Chemical Society 2012, 57, 1095-1098, http://dx.doi.org/10.4067/S0717-97072012000200007.

12. Kristanti, R.A.; Kambe, M.; Hadibarata, T.; Toyama, T.; Tanaka, Y.; Mori, K. Isolation and characterization of 3-nitrophenol-degrading bacteria associated with rhizosphere of Spirodela polyrrhiza. Environmental Science and Pollution Research 2012, 19, 1852-1858, https://doi.org/10.1007/s11356-012-0836-x.

13. Hadibarata, T.; Tachibana, S.; Itoh, K. Biodegradation of $n$-Eicosane by Fungi Screened from Nature. Pakistan Journal of Biological Sciences $2007, \quad$ 10, http://dx.doi.org/10.3923/pjbs.2007.1804.1810.

14. Tang, K.H.D. Municipal Solid Waste Management in the Sarawak State of Malaysia and the Way Forward. Asian Journal of Environment \& Ecology 2020, 38-55, https://doi.org/10.9734/ajee/2020/v12i230157.

15. Ramankutty, N.; Mehrabi, Z.; Waha, K.; Jarvis, L.; Kremen, C.; Herrero, M.; Rieseberg, L. Trends in Global Agricultural Land Use: Implications for Environmental Health and Food Security. Annu. Rev. Plant Biol. 2018, 69, https://doi.org/10.1146/annurev-arplant-042817-040256.

16. Nazifa, T.H.; Habba, N.; Salmiati; Aris, A.; Hadibarata, T. Adsorption of Procion Red MX-5B and Crystal Violet Dyes from Aqueous Solution onto Corncob Activated Carbon. J. Chin. Chem. Soc. 2018, 65, 259270, https://doi.org/10.1002/jccs.201700242.

17. Rahmat, N.A.; Hadibarata, T.; Yuniarto, A.; Elshikh, M.S.; Syafiuddin, A. Isotherm and kinetics studies for the adsorption of bisphenol A from aqueous solution by activated carbon of Musa acuminata. IOP Conference Series: Materials Science and Engineering 2019, 495, 012059, https://doi.org/10.1088/1757899x/495/1/012059.

18. Ayawei, N.; Ebelegi, A.N.; Wankasi, D. Modelling and Interpretation of Adsorption Isotherms. Journal of Chemistry 2017, 2017, 3039817, https://doi.org/10.1155/2017/3039817.

19. Kuang, Y.; Zhang, X.; Zhou, S. Adsorption of Methylene Blue in Water onto Activated Carbon by Surfactant Modification. Water 2020, 12, https://doi.org/10.3390/w12020587.

20. Abd-Elhamid, A.I.; Emran, M.; El-Sadek, M.H.; El-Shanshory, A.A.; Soliman, H.M.A.; Akl, M.A.; Rashad, M. Enhanced removal of cationic dye by eco-friendly activated biochar derived from rice straw. Applied Water Science 2020, 10, 45, https://doi.org/10.1007/s13201-019-1128-0. 
21. Abdelhameed, R.M.; Abdel-Gawad, H.; Hegazi, B. Effective adsorption of prothiofos (O-2,4-dichlorophenyl O-ethyl S-propyl phosphorodithioate) from water using activated agricultural waste microstructure. Journal of Environmental Chemical Engineering 2020, 8, 103768, https://doi.org/10.1016/j.jece.2020.103768.

22. Al-Ghouti, M.A.; Al-Absi, R.S. Mechanistic understanding of the adsorption and thermodynamic aspects of cationic methylene blue dye onto cellulosic olive stones biomass from wastewater. Sci. Rep. 2020, 10, 15928, https://doi.org/10.1038/s41598-020-72996-3.

23. Mu, T.-H.; Sun, H.-N. Chapter 22 - Sweet Potato Leaf Polyphenols: Preparation, Individual Phenolic Compound Composition and Antioxidant Activity. In Polyphenols in Plants (Second Edition), Watson, R.R., Ed. Academic Press: 2019. 365-380, https://doi.org/10.1016/B978-0-12-813768-0.00022-0.

24. Jasper, E.E.; Ajibola, V.O.; Onwuka, J.C. Nonlinear regression analysis of the sorption of crystal violet and methylene blue from aqueous solutions onto an agro-waste derived activated carbon. Applied Water Science 2020, 10, 132, https://doi.org/10.1007/s13201-020-01218-y. 